\title{
Relationship among Eating Behavior, Effortful Control, and Working Memory in Female Young Adults
}

\section{Katsumasa Momoi ${ }^{1,2}$, Kumiko Ohara1, Yoshimitsu Okita ${ }^{3}$, Tomoki Mase ${ }^{4}$, Chiemi Miyawaki $^{5}$, Tomoko Fujitani ${ }^{1}$, Harunobu Nakamura ${ }^{1}$}

${ }^{1}$ Graduate School of Human Development and Environment, Kobe University, Kobe, Japan

${ }^{2}$ Faculty of Health and Welfare, Tokushima Bunri University, Tokushima, Japan

${ }^{3}$ Graduate School of Engineering, Shizuoka University, Hamamatsu, Japan

${ }^{4}$ Faculty of Human Development and Education, Kyoto Women's University, Kyoto, Japan

${ }^{5}$ Department of Early Childhood Education, Heian Jogakuin (St. Agnes') College, Kyoto, Japan

Email: hal@kobe-u.ac.jp

How to cite this paper: Momoi, K., Ohara, K., Okita, Y., Mase, T., Miyawaki, C., Fujitani, T. and Nakamura, H. (2016) Relationship among Eating Behavior, Effortful Control, and Working Memory in Female Young Adults. Health, 8, 1187-1194. http://dx.doi.org/10.4236/health.2016.812122

Received: August 3, 2016

Accepted: September 4, 2016

Published: September 7, 2016

Copyright $\odot 2016$ by authors and Scientific Research Publishing Inc. This work is licensed under the Creative Commons Attribution International License (CC BY 4.0).

http://creativecommons.org/licenses/by/4.0/ (c) (i) Open Access

\section{Abstract}

The management of eating behavior plays an important role in health maintenance. In this study, we investigated the relationship between eating behavior and effortful control in female young adults. Participants completed the questionnaire measures of effortful control and eating behaviors and Stroop cognitive interference task. The results showed that restrained eating was positively correlated with activation control; emotional eating was negatively correlated with inhibitory control and attentional control; external eating was negatively correlated with inhibitory, activation, and attentional control. The scores for activation control and restrained eating were higher for participants with a low Stroop error rate than for those with a high Stroop error rate. These results indicate that restrained eating has a different association with effortful control than doing emotional and external eating.

\section{Keywords}

Executive Function, Working Memory, Effortful Control, Eating Behavior

\section{Introduction}

The management of eating behavior plays an important role in health maintenance. However, it is not easy for individuals to decide how much and what to eat, because the type and quantity of food eaten vary according to individual characteristics such as age, gender, amount of physical activity, and preference. 
Effortful control is the ability to inhibit a dominant response and to perform instead a subdominant response [1]. That is, effortful control is the ability to voluntarily activate or inhibit impulses to act [2]. Effortful control is involved by attention [1]. Attention is a multifaceted cognitive domain that is required for efficient perception, learning, memory, and reasoning. Research has shown that effortful control is related to eating pathology [3]-[5]. In one study, patients with eating disorders and bingeing/ purging behavior scored significantly lower on the Effortful Control Scale (ECS) [6]. In contrast, other studies have found that effortful control is not associated with severe weight cycling [7], and that the interaction between sensitivity to reward and effortful control does not predict weight cycling [7]. Although some research shows no association between effortful control and eating behaviors [8], other research indicates that lower effortful control is associated with more eating disorder symptoms [9]. In one study, eating disorder symptoms were related to low levels of effortful control and strongly related to high levels of Behavioral Inhibition Scale reactivity (anxiety) [10]. Thus, the findings in this area are contradictory.

Working memory is conceptualized in executive function [11], and is the active process by which information is maintained in short-term memory stores and manipulated during performance of complex, goal-directed tasks [12]. It is reported that executive function and effortful control are associated and overlapping constructs [13]. Indeed, working memory is considered vital to higher-order cognitive abilities such as planning [14], problem solving [15], delayed goal execution [16] and overall fluid intelligence [17] [18]. Therefore, working memory is considered important in the management of eating behavior.

In this study, we investigated the relationship among eating behavior, effortful control and working memory in female young adults.

\section{Materials and Methods}

\subsection{Participants}

Participants were 26 female Japanese university students (age $20.6 \pm 0.5$ years). The inclusion criteria were females aged between 20 and 22 years. Participants completed an anonymous questionnaire that included items related to cognitive function and eating behavior.

All participants provided informed consent and the study received the approval of the Human Ethics Committee of the Graduate School of Human Development and Environment, Kobe University.

\subsection{Measures}

To measure effortful control, we used the Japanese version of the ECS [19], which was developed from the original ECS included in the Adult Temperament Questionnaire [20]. The Japanese version of the ECS consists of 35 items, each of which is rated on a 4-point Likert scale (untrue $=1$, slightly untrue $=2$, slightly true $=3$, true $=4$ ) to yield a total score ranging between 35 and 140. It includes the following three subscale scores: 
1) the ability to voluntarily manage attention (attentional control or the ability to focus/shift attention when needed = EC-attentional [12 items, range 12 - 48]); 2) the ability to inhibit a dominant response (inhibitory control or the ability to inhibit behavior = EC-inhibitory [11 items, range $11-44]$ ); and 3) the ability to activate a subdominant response (activation control or the ability to activate behavior = EC-activation [12 items, range 12 - 48]).

Eating behavior was assessed using the Japanese version of the Dutch Eating Behavior Questionnaire (DEBQ) [21] originally developed by van Strien [22]. The validity and reliability of the Japanese version of the DEBQ has been evaluated in a previous study [21]. The DEBQ is a 33-item self-rated questionnaire comprising three subscales: restrained eating (10 items), emotional eating (13 items), and external eating (10 items). Restrained eating is paradoxical dietary restraint (food intake is initially reduced to lose or maintain body weight, but is followed by increased consumption and binge eating). Emotional eating is eating in response to negative emotions, and external eating is eating in response to the sight or smell of food [22]. Participants rated each DEBQ question from 1 for "never" to 5 for "very often". Responses to each question were added together for each subscale, and then divided by the number of questions on each subscale to produce a score between 1 and 5 .

The Stroop task was used to measure cognitive interference. In the Stroop interference task, participants are required to name the color of a written color word displayed on the monitor while inhibiting the tendency to read the word itself. Inhibitory control is required when the color in which the word is printed and the color denoted by the word are incongruent. In the present study, we used a computerized version of the Stroop task, which included two experimental blocks (one congruent, one incongruent) of 40 trials each. Congruent trials consisted of color words that were displayed in the corresponding color. In incongruent trials, the color of the color word was different to the color denoted by the word. The error response rate was calculated by dividing the number of error trials by the total number of trials.

\subsection{Data Analysis}

Pearson's product-moment correlation coefficient was used to test the association between cognitive function and eating behavior. Student's t-test was used to evaluate the between-group difference. The statistical level for significance was set at 0.05 . Statistical analysis was performed using SPSS ${ }^{\circledR} 22.0 \mathrm{~J}$ for Windows (SPSS Inc., Chicago, USA).

\section{Results}

The mean ECS scores (for inhibitory control, activation control, and attentional control) and DEBQ scores are shown in Table 1. Using the Stroop task error rate, participants were divided into two groups: a high error group and a low error group.

Table 2 shows the relationship between DEBQ and ECS scores. Restrained eating was significantly positively correlated with activation control $(r=0.508, p<0.001)$. Emotional eating was significantly negatively correlated with inhibitory control $(r=$ 
Table 1. Effortful control, eating behavior, and Stroop test scores $(\mathrm{n}=26)$.

\begin{tabular}{cc}
\hline Subscale & Score \\
ECS & $31.0 \pm 4.7$ \\
Inhibitory control & $32.0 \pm 5.1$ \\
Activation control & $28.1 \pm 5.5$ \\
Attentional control & \\
DEBQ & $30.6 \pm 6.9$ \\
Restrained eating & $28.3 \pm 11.4$ \\
Emotional eating & $35.9 \pm 5.5$ \\
External eating & \\
Stroop test (interference) & $3.2 \pm 4.6$ \\
Error Rates & \\
\hline
\end{tabular}

Data are mean \pm standard deviation. ECS: Effortful Control Scale, DEBQ: Dutch Eating Behavior Questionnaire.

Table 2. Correlation coefficients between eating behavior and effortful control.

\begin{tabular}{cccc}
\hline & Inhibitory Control & Activation control & Attentional Control \\
\hline Restrained eating & 0.252 & $0.508^{*}$ & 0.081 \\
Emotional eating & $-0.407^{*}$ & 0.338 & -0.088 \\
External eating & $-0.769^{*}$ & $-0.696^{*}$ & $-0.454^{*}$ \\
\hline
\end{tabular}

Data are Pearson's correlation coefficients. ${ }^{*} \mathrm{p}<0.05$.

$-0.407, \mathrm{p}<0.001)$. External eating was significantly negatively correlated with inhibitory control $(\mathrm{r}=-0.769, \mathrm{p}<0.001)$, activation control $(\mathrm{r}=-0.696, \mathrm{p}=0.002)$, and attentional control $(\mathrm{r}=-0.454, \mathrm{p}<0.001)$.

Table 3 shows that the DEBQ scores for restrained eating were significantly higher for participants in the low error rate group than for those in the high error rate group $(p<0.001)$. In addition, the ECS scores for activation control were significantly higher for participants in the low error rate group than for those in the high error rate group $(\mathrm{p}<0.001)$.

\section{Discussion}

We attempted to clarify the relationship between eating behavior and effortful control in Japanese female students. We also verified the association of working memory with eating behavior and effortful control.

First, restrained eating was positively correlated with activation control. Emotional eating was negatively correlated with inhibitory and attentional control, and external eating was negatively correlated with inhibitory control, activation control, and attentional control. Effortful control is the ability to inhibit a dominant response and to perform instead a subdominant response [1]. Activation control is the capacity to perform 
Table 3. Association of Stroop test scores with effortful control and eating behavior.

\begin{tabular}{ccc}
\hline & Low error rate group $(\mathrm{n}=12)$ & High error rate group $(\mathrm{n}=14)$ \\
\hline ECS & $32.3 \pm 4.3$ & $29.1 \pm 5.0$ \\
Inhibitory control & $34.1 \pm 4.4^{*}$ & $29.6 \pm 5.0$ \\
Activation control & $28.6 \pm 5.5$ & $27.2 \pm 6.0$ \\
Attentional control & & \\
DEBQ & $33.9 \pm 5.1^{*}$ & $26.5 \pm 6.0$ \\
Restrained eating & $28.1 \pm 9.6$ & $28.4 \pm 12.7$ \\
Emotional eating & $34.3 \pm 4.8$ & $37.4 \pm 5.7$ \\
External eating & & \\
\hline
\end{tabular}

Data are mean \pm standard deviation. ${ }^{*}$ Student's t-test showed a significant difference between the low error rate group and the high error rate group $(\mathrm{p}<0.05)$. ECS: Effortful Control Scale, DEBQ: Dutch Eating Behavior Questionnaire.

an action when there is a strong tendency to avoid it [1]. Emotional eating and external eating are associated with disinhibition [23]. Disinhibition in eating behavior, which is partly characterized by the propensity to eat opportunistically in response to environmental cues, has long been associated with obesity in both youths and adults [24]. Previous work has shown that disinhibition is also negatively related to restrained eating [22]. These researches support the present findings. Thus, the present findings indicate that effortful control relates differently to restrained eating, emotional eating, and external eating.

Second, scores for activation control and restrained eating were higher in the low error rate group than in the high error rate group. One aspect of attention has been conceptualized in the model of working memory [12] [25]. Working memory is the active process by which information is maintained in short-term memory stores and manipulated during performance of complex, goal-directed tasks [12]. Previous studies have shown that better working memory is associated with higher effortful control in both children [26] and adults [27]. The present findings are not inconsistent with these results.

Some previous reports on the relationship between working memory and eating behaviors have found that uncontrolled eating is associated with low levels of working memory [28]. Rigid restraint is associated with attentional bias to food and shape-related stimuli, whereas flexible restraint correlates with impaired working memory [29]. Other studies have found associations between dieting and poorer working memory performance [30] [31]. In contrast, the present findings show that restrained eating was higher in the group with better working memory performance than in the group with poorer performance. The reasons behind this pattern of results are not clear. However, consistent and sustained eating restraint is needed to control food intake and lose weight, and this may require working memory. Future research should examine this possibility. 
Two study limitations should be noted. This study used a cross-sectional design, which limits the possibility of drawing inferences about the direction of effects. In addition, our samples were convenience samples drawn from a limited area of Japan, and the number of the samples was a little less.

\section{Conclusion}

In the present study, restrained eating was positively correlated with activation control; emotional eating was negatively correlated with inhibitory control and attentional control; external eating was negatively correlated with inhibitory, activation, and attentional control. Activation control and restrained eating scores were higher in the low error rate group than in the high error rate group. These findings indicate that restrained eating has a different association with executive functions than doing emotional and external eating.

\section{Acknowledgements}

The authors thank the participants of the study.

\section{Conflict of Interest}

The authors report no conflicts of interest in this work.

\section{References}

[1] Rothbart, M.K. and Bates, J.E. (2006) Temperament. In: Eisenberg, N., Damon, W. and Lerner, R.M., Eds., Handbook of Child Psychology, 6th Edition, Social, Emotional, and Personality Development, Wiley, New York, 99-166.

[2] Derryberry, D. and Rothbart, M.K. (1997) Reactive and Effortful Processes in the Organization of Temperament. Development and Psychopathology, 9, 633-652. http://dx.doi.org/10.1017/S0954579497001375

[3] Claes, L., Robinson, M.D., Muehlenkamp, J.J., Vandereycken, W. and Bijttebier, P. (2010) Differentiating Bingeing/Purging and Restrictive Eating Disorder Subtypes: The Roles of Temperament, Effortful Control, and Cognitive Control. Personality and Individual Differences, 48, 166-170. http://dx.doi.org/10.1016/j.paid.2009.09.016

[4] Kitsantas, A., Gilligan, T.D. and Kamata, A. (2003) College Women with Eating Disorders: Self-Regulation, Life Satisfaction, and Positive/Negative Affect. The Journal of Psychology, 137, 381-395. http://dx.doi.org/10.1080/00223980309600622

[5] Stice, E. (2001) A Prospective Test of the Dual-Pathway Model of Bulimic Pathology: Mediating Effects of Dieting and Negative Affect. Journal of Abnormal Psychology, 110, 124135. http://dx.doi.org/10.1037/0021-843X.110.1.124

[6] Claes, L., Mitchell, J.E. and Vandereycken, W. (2012) Out of Control? Inhibition Processes in Eating Disorders from a Personality and Cognitive Perspective. International Journal of Eating Disorders, 45, 407-414. http://dx.doi.org/10.1002/eat.20966

[7] Zwaan, M., Engeli, S. and Muller, A. (2015) Temperamental Factors in Severe Weight Cycling. A Cross-Sectional Study. Appetite, 91, 336-342. http://dx.doi.org/10.1016/j.appet.2015.04.064

[8] Leung, C.Y., Miller, A.L., Kaciroti, N.A., Chen, Y.P., Rosenblum, K. and Lumeng, J.C. 
(2015) Low-Income Pre-Schoolers with Higher Temperamental Surgency Enjoy and Respond More to Food, Mediating the Path to Higher Body Mass Index. Pediatric Obesity, 11, 181-186. http://dx.doi.org/10.1111/ijpo.12042

[9] Burt, N.M., Boddy, L.E. and Bridgett, D.J. (2015) Contribution of Temperament to Eating Disorder Symptoms in Emerging Adulthood: Additive and Interactive Effects. Eating Behaviors, 18, 30-35. http://dx.doi.org/10.1016/j.eatbeh.2015.03.010

[10] Claes, L., Bijttebier, P., Mitchell, J.E., de Zwaan, M. and Mueller, A. (2011) The Relationship between Compulsive Buying, Eating Disorder Symptoms, and Temperament in a Sample of Female Students. Comprehensive Psychiatry, 52, 50-55. http://dx.doi.org/10.1016/j.comppsych.2010.05.003

[11] Miyake, A., Friedman, N.P., Emerson, M.J., Witzki, A.H., Howerter, A. and Wager, T.D. (2000) The Unity and Diversity of Executive Functions and Their Contributions to Complex "Frontal Lobe" Tasks: A Latent Variable Analysis. Cognitive Psychology, 41, 49-100. http://dx.doi.org/10.1006/cogp.1999.0734

[12] Baddeley, A. (2012) Working Memory: Theories, Models, and Controversies. Annual Review of Psychology, 63, 1-29. http://dx.doi.org/10.1146/annurev-psych-120710-100422

[13] Bridgett, D.J., Oddi, K.B., Laake, L.M., Murdock, K.W. and Bachmann, M.N. (2012) Integrating and Differentiating Aspects of Self-Regulation: Effortful Control, Executive Functioning, and Links to Negative Affectivity. Emotion, 13, 47-63.

http://dx.doi.org/10.1037/a0029536

[14] Phillips, L.H., Wynn, V., Gilhooly, K.J., Della Sala, S. and Logie, R.H. (1999) The Role of Memory in the Tower of London Task. Memory, 7, 209-231. http://dx.doi.org/10.1080/741944066

[15] Logie, R.H., Gilhooly, K.J. and Wynn, V. (1994) Counting on Working Memory in Arithmetic Problem Solving. Memory \& Cognition, 22, 395-410. http://dx.doi.org/10.3758/BF03200866

[16] Brewer, G.A., Knight, J.B., Marsh, R.L. and Unsworth, N. (2010) Individual Differences in Event-Based Prospective Memory: Evidence for Multiple Processes Supporting Cue Detection. Memory \& Cognition, 38, 304-311. http://dx.doi.org/10.3758/MC.38.3.304

[17] Engle, R.W., Tuholski, S.W., Laughlin, J.E. and Conway, A.R. (1999) Working Memory, Short-Term Memory, and General Fluid Intelligence: A Latent-Variable Approach. Journal of Experimental Psychology General, 128, 309-331. http://dx.doi.org/10.1037/0096-3445.128.3.309

[18] Shelton, J.T., Elliott, E.M., Matthews, R.A., Hill, B.D. and Gouvier, W.D. (2010) The Relationships of Working Memory, Secondary Memory, and General Fluid Intelligence: Working Memory Is Special. Journal of Experimental Psychology Learning, Memory, and Cognition, 36, 813-820. http://dx.doi.org/10.1037/a0019046

[19] Yamagata, S., Takahashi, Y., Shigematsu, K., Ono, Y. and Kijima, N. (2005) Development and Validation of Japanese Version of Effortful Control Scale for Adults. Japanese Journal of Personality, 14, 30-41. http://dx.doi.org/10.2132/personality.14.30

[20] Rothbart, M.K., Ahadi, S.A. and Evans, D.E. (2000) Temperament and Personality: Origins and Outcomes. Journal of Personality and Social Psychology, 78, 122-135. http://dx.doi.org/10.1037/0022-3514.78.1.122

[21] Imada, S. (1994) Psychological Studies about Eating Behavior(3): A Japanese Version of the Dutch Eating Behavior Questionnaire (Debq). Studies in the Humanities \& Sciences, 34, 281-291.

[22] Van Strien, T., Frijters, J.E.R., Bergers, G.P.A. and Defares, P.B. (1986) The Dutch Eating 
Behavior Questionnaire (Debq) for Assessment of Restrained, Emotional, and External Eating Behavior. International Journal of Eating Disorders, 5, 295-315. http://dx.doi.org/10.1002/1098-108X(198602)5:2<295::AID-EAT2260050209>3.0.CO;2-T

[23] Kim, K.K., Suh, H.S., Hwang, I.C. and Ko, K.D. (2014) Influence of Eating Behaviors on Short-Term Weight Loss by Orlistat and Anorectic Agent. Eating Behaviors, 15, 87-90. http://dx.doi.org/10.1016/j.eatbeh.2013.10.019

[24] Stunkard, A.J. and Messick, S. (1985) The Three-Factor Eating Questionnaire to Measure Dietary Restraint, Disinhibition and Hunger. Journal of Psychosomatic Research, 29, 71-83. http://dx.doi.org/10.1016/0022-3999(85)90010-8

[25] Baddeley, A.D. and Hitch, G. (1974) Working Memory. In: Bower, G.H., Ed., The Psychology of Learning and Motivation: Advances in Research and Theory, Academic Press, New York, 47-89. http://dx.doi.org/10.1016/S0079-7421(08)60452-1

[26] González, C., Fuentes, L.J., Carranza, J.A. and Estévez, A.F. (2001) Temperament and Attention in the Self-Regulation of 7-Year-Old Children. Personality and Individual Differences, 30, 931-946. http://dx.doi.org/10.1016/S0191-8869(00)00084-2

[27] Bridgett, D.J., Oddi, K.B., Laake, L.M., Murdock, K.W. and Bachmann, M.N. (2013) Integrating and Differentiating Aspects of Self-Regulation: Effortful Control, Executive Functioning, and Links to Negative Affectivity. Emotion, 13, 47-63.

http://dx.doi.org/10.1037/a0029536

[28] Calvo, D., Galioto, R., Gunstad, J. and Spitznagel, M.B. (2014) Uncontrolled Eating Is Associated with Reduced Executive Functioning. Clinical Obesity, 4, 172-179.

http://dx.doi.org/10.1111/cob.12058

[29] Westenhoefer, J., Engel, D., Holst, C., Lorenz, J., Peacock, M., Stubbs, J., Whybrow, S. and Raats, M. (2013) Cognitive and Weight-Related Correlates of Flexible and Rigid Restrained Eating Behaviour. Eating Behaviors, 14, 69-72. http://dx.doi.org/10.1016/j.eatbeh.2012.10.015

[30] Green, M.W. and Rogers, P.J. (1998) Impairments in Working Memory Associated with Spontaneous Dieting Behaviour. Psychological Medicine, 28, 1063-1070. http://dx.doi.org/10.1017/S0033291798007016

[31] Verstraeten, K., Vasey, M.W., Raes, F. and Bijttebier, P. (2009) Temperament and Risk for Depressive Symptoms in Adolescence: Mediation by Rumination and Moderation by Effortful Control. Journal of Abnormal Child Psychology, 37, 349-361. http://dx.doi.org/10.1007/s10802-008-9293-x 
Submit or recommend next manuscript to SCIRP and we will provide best service for you:

Accepting pre-submission inquiries through Email, Facebook, LinkedIn, Twitter, etc. A wide selection of journals (inclusive of 9 subjects, more than 200 journals)

Providing 24-hour high-quality service

User-friendly online submission system

Fair and swift peer-review system

Efficient typesetting and proofreading procedure

Display of the result of downloads and visits, as well as the number of cited articles

Maximum dissemination of your research work

Submit your manuscript at: http://papersubmission.scirp.org/ 